\title{
Lectures du Procès des Juntes en Argentine : production intellectuelle, (re)productions mémorielles
}

\author{
David Copello, \\ Doctorant en Théorie Politique à Sciences Po/CEVIPOF (Paris).
}

Le « mouvement des droits de l'Homme » surgi en Argentine pendant la dernière dictature (1976-1983) est sans doute un des phénomènes socio-politiques les plus commentés dans les travaux ayant trait à l'histoire contemporaine de ce pays. Quand on se penche sur la littérature locale de sciences sociales traitant de l'influence du mouvement des droits de l'Homme sur la « transition démocratique » argentine et, de manière plus générale, sur la culture politique de la période post-dictatoriale, on ne peut que remarquer l'importance accordée au Procès des Juntes qui se tient au long de l'année 1985. Le statut de cet événement sera ici partiellement remis en cause, à travers une analyse critique de la littérature académique qui lui est consacrée. Cet article s'inscrit dans le cadre d'une recherche pour laquelle nous avons été amené à consulter à la fois des textes scientifiques " de référence ", publiés de la date du procès à nos jours, et des textes de nature plutôt archivistique, tels que des articles de la presse militante d'époque. Ce double corpus sera abordé via deux échantillons : d'un côté, les travaux de cinq auteurs universitaires et leurs sources ; de l'autre, les publications des réseaux éditoriaux proches de l'association Madres de Plaza de Mayo. Un des enjeux de ce papier, à travers le cas du Procès des Juntes, va alors être de déconstruire la double distinction entre source et référence, entre intervention politique et travail académique. Il s'agira de montrer, à travers l'analyse de données textuelles et para-textuelles, 1) les logiques qui permettent de reconnecter la pratique politique et la pratique scientifique au sein d'une configuration académique et éditoriale donnée, 2) l'importance à accorder aux modes de circulation de tous ces textes pour comprendre la mise en place d'une mémoire historique donnée.

Au premier abord, le «mouvement des droits de l'Homme », la «transition démocratique » et la procédure judiciaire semblent être des processus convergents et complémentaires, témoins d'une culture politique nouvelle, promouvant le Droit plutôt que la force. Nombre des études portant sur le processus de «transition démocratique » en Argentine reposent en effet sur un découpage séquentiel identique. La dynamique transitionnelle serait enclenchée par un certain nombre d'associations de défense des droits de l'Homme qui se constituent en « mouvement des droits de l'Homme » $1(\mathrm{MDH})$, structuré autour de la défense du « droit à la vie » face à la répression criminelle des opposants par les militaires. Les revendications de ce mouvement sont généralement ramenées à une double demande de vérité (sur le sort réservé aux victimes, notamment les " disparus ») et de justice. À cette première séquence du processus transitionnel succéderait une période faste, marquée par le retour à un État de droit à la fin de l'année 1983, avec l'élection de Raúl Alfonsín à la Présidence de la République, sur un programme reprenant les revendications du « MDH ». Le point culminant de cette seconde période est incarné par le Procès des Juntes, dont les audiences publiques se tiennent du 22 avril au 9 décembre 1985, jour où la sentence est prononcée. Cette séquence où semble régner un consensus au sujet des droits de l'Homme entre le gouvernement et les mouvements sociaux qui s'en réclament, laisserait ensuite place à une période de reflux, au cours de laquelle les autorités, dans un contexte de tensions avec l'armée, choisiront de mettre un terme, par la voie législative, aux poursuites judiciaires contre les militaires. On distinguerait donc trois séquences : l'émergence contestataire d'une culture des droits grâce au « MDH »; le « consensus alfonsiniste sur les droits de l'Homme » 2, couronné par le Procès des Juntes ; puis le renoncement aux procès contre les militaires.

À partir de cette périodisation, si on cherche à schématiser les interactions entre le " MDH », le gouvernement et l'instance judiciaire telles qu'elles sont présentées en général, on observe que : a) quand le gouvernement soutient la tenue de procès contre les militaires (1983-1985), le « $\mathrm{MDH}$ » le soutient ; b) quand le gouvernement agit en sens inverse (à partir de 1986), le « MDH » devient son opposant. La revendication de «Vérité et Justice » qui est au cour du « MDH » pourrait donc être entendue comme une identification à l'instance judiciaire : la culture des droits militerait pour une culture judiciaire3, l'une et l'autre seraient indistinctes. Si tel est le cas, le nœud de ces interactions doit se situer dans le moment du procès, dans l'intervention de l'État à travers l'instance judiciaire : celle-ci serait la manifestation d'un équilibre idéal, d'une osmose des trois acteurs. Il s'agira ici de questionner cette évidence, pour faire apparaître les tensions qui précèdent le recul du gouvernement sur la question des droits de l'Homme.

On se demandera donc dans quelle mesure la culture des droits véhiculée par le «MDH » se retrouve véritablement dans les procédures judiciaires telles qu'elles se sont déroulées. Le respect et la mise en application de la procédure pénale (qui renvoient à ce que nous résumons ici sous l'expression « culture judiciaire ») sont-ils vraiment la concrétisation des objectifs démocratiques du « MDH »? Qu'est-ce qui permet d'expliquer que cette association problématique apparaisse comme une évidence dans la littérature ?

On verra dans un premier temps comment le procès a pu être traité par un certain nombre d'auteurs comme un marqueur démocratique à caractère fondateur : le nouveau régime politique, dont les valeurs s'incarneraient dans une culture judiciaire, serait la consécration de la culture des droits diffusée par le «MDH ». Ce constat sera ensuite nuancé, en mettant en évidence certains des conflits qui ont entouré la tenue de ce procès, et en particulier les réactions négatives qu'il a pu susciter dans une partie du «MDH ». Ceci nous mènera à interroger le statut de la bibliographie « savante » qui domine le champ d'études sur le «MDH » en Argentine : courant d'opinion se perpétuant à travers une série de processus d'auto-citation, elle contribue à la circulation d'une mémoire que nous qualifierons de « procéduraliste ».

\section{Le procès : point culminant du processus de démocratisation?}

Dans la bibliographie contemporaine sur la «transition démocratique », ce procès occupe une place de choix. Certains consacrent des ouvrages entiers à un de ses aspects, comme Claudia Feld qui étudie le traitement des images-vidéo des audiences4. D’autres, dans des travaux plus généraux, ne manquent pas de lui octroyer un traitement privilégié : Marcos Novaro, par exemple, réserve un des huit chapitres de sa somme d'histoire politique sur les années 1983-2001 au traitement de la seule année 1985, mettant en exergue le déroulement du procès au même titre que la politique économique, dans ce qui est présenté comme le dernier cycle à bilan positif du gouvernement d'Alfonsín5. Mais en dépit de ces occurrences multiples, la valeur du procès dans le processus transitionnel ne va pas de soi.

En effet, si on ne fait que considérer la peine prononcée au terme des audiences, sa qualité de marqueur démocratique ne saute pas aux yeux. Sur les neuf dirigeants des trois premières Juntes qui sont jugés à cette occasion, seuls trois sont condamnés à des peines réellement lourdes compte tenu des faits qui leur sont reprochés (vol, enlèvement, torture et meurtre de centaines d'individus innocents). Quatre des accusés sont même blanchis, entre autres parce que la Cour ne reconnaît pas la responsabilité conjointe des différents corps d'armée dans l'organisation du plan répressifㅁ. Les peines sont donc relativement modérées, surtout si on tient compte du fait que d'autres responsables de la répression, de moindre hiérarchie, subissent quelques mois plus tard des condamnations parfois plus lourdes au cours de procès qui ont lieu en parallèle7. Comment expliquer alors qu'on puisse octroyer une telle importance à ce procès, et considérer qu'il a malgré tout donné lieu à un châtiment « exemplaire » $\underline{8}$ ? 
Pour répondre à cette question, nous nous basons sur l'analyse d'un premier corpus constitué de huit textes universitaires contemporains, publiés entre 2002 et 2010 par cinq auteurs différents : Emilio Crenzel9, Claudia Feldı̄o, Roberto Gargarella11, Marcos Novaro12 et Hugo Vezzetti13. Écrits par des auteurs ayant diverses positions dans le champ académique - les profils plutôt « intellectuels » côtoyant les profils plus « professionnels »-, ces travaux issus de perspectives variées abordent tous à un moment ou à un autre le procès à travers des prismes très divers, du plus large au plus restreint. Tous, alors qu'ils écrivent deux décennies après les faits, s'accordent cependant sur la centralité de cet événement, qu'ils soulignent de deux types de manières : d'une part, en insistant sur l'enjeu symbolique que revêt la tenue même du procès et, d'autre part, en pointant sa diffusion, son impact social sans commune mesure avec celui des autres procédures judiciaires. Nous détaillerons ces différents aspects présents dans le corpus académique, pour ensuite les confronter à un second corpus constitué essentiellement de textes extraits de la presse militante d'époque, qui se constitue en " camp » adverse, dans la mesure où la vision du procès qui y est donnée est radicalement différente. Tenons-nous en toutefois, pour le moment, au premier ensemble.

Si la tenue du procès y acquiert à elle seule un tel poids symbolique, c'est pour au moins trois raisons. D’abord, parce que le jugement d'anciens dictateurs est alors un fait inédit non seulement en Argentine, mais aussi dans toutes les transitions post-autoritaires latino-américaines. En deuxième lieu, parce que le fait de « mener devant la Justice des chefs militaires qui, jusqu'il y a peu, étaient encore tout puissants, représentait pour quiconque l'affirmation indiscutable du principe d'égalité devant la loi »14. En effet, les anciens maitres de l'État semblent se retrouver dans la position du simple citoyen : c'est en tout cas ce qui est impliqué dans la mise en scène du procès, qui les voit occuper le siège des accusés, même si, dans les faits, le traitement équitable de leur cas n'est pas acquis. Cette insistance sur la mise en scène se retrouve d'ailleurs - et c'est le troisième argument - chez Hugo Vezzetti, sans doute l'auteur contemporain qui fait preuve du plus grand enthousiasme pour le procès. Pour lui, " dans cette dimension théâtrale, les effets symboliques du procès allaient au-delà de la simple administration de la justice pour se constituer en événement fondateur qui, envisagé aujourd'hui, prend la dimension d'un mythe "15. Ce qui est intéressant dans cette approche louangeuse, c'est qu'un lien est tissé entre l'instance judiciaire et un autre des acteurs centraux de la période :

Du point de vue de son impact institutionnel et politique, ce que le procès mettait en accusation, alors, allait au-delà des crimes, dans la mesure où il faisait référence à la destruction d'un ordre juridique, c'est-à-dire au processus de criminalisation de l'État. En fin de compte, les conditions pour conquérir la paix pouvaient être synthétisées par deux principes et deux valeurs qui s'étaient imposés à travers la lutte du mouvement des droits de l'Homme : la vérité et la justice $\underline{16}$.

Un trait d'union est donc tiré entre ce processus de rétablissement de l'ordre juridique - qui s'exprime dans la tenue du procès tout en le débordant par la création d'un nouveau sens commun démocratique, une véritable culture judiciaire - et le « $\mathrm{MDH}$ » $:$ l'un serait la concrétisation des revendications de l'autre. La culture judiciaire réaliserait ainsi la culture des droits qui l'a rendue possible.

Mais le caractère « exemplaire » du Procès des Juntes ne se résume pas à la symbolique qu'il véhicule : on en rend compte, aussi, en insistant sur les canaux de diffusion de cette symbolique, parfois ramenés à une adhésion pure et simple du public. L'idée est résumée, encore une fois, chez Vezzetti qui, évoquant le risque d'un soulèvement militaire en opposition aux poursuites judiciaires, considère que « si ce procès a pu avoir lieu, c'est parce qu’il faisait consensus dans la société, qui lui apportait son soutien »17. Sans aller jusqu'à en tirer des conclusions générales sur l'état d'esprit de " la société », d'autres auteurs témoignent de l'impact social sans commune mesure du procès, par la massivité des canaux qui en retransmettent le déroulement. Outre le fait que les audiences sont publiques, ce qui est rare à l'époque en Argentine, elles sont qui plus est filmées : chaque jour, la télévision en diffuse des extraits18. Ceux qui souhaitent accéder à un compte-rendu plus détaillé peuvent, quant à eux, lire l'hebdomadaire El Diario del juicio. Claudia Feld note que cette publication, distribuée de mai 1985 à janvier 1986 et dans laquelle est consignée la quasi-totalité des témoignages et des débats qu'ils suscitent, sera vendue en moyenne à 70.90o exemplaires par semaine19. Le procès est donc bien un événement de grande envergure de par sa "vaste diffusion "20. Suscite-t-il pour autant de l'adhésion, au sens où l'entend Hugo Vezzetti ? Dans quelle mesure la société argentine est-elle imprégnée de culture judiciaire ? Le seul élément qui semble attester de ce soutien social au procès est la marche organisée le jour de la première audience. Celle-ci est mentionnée, par exemple, par Emilio Crenzel :

le procès commença le 22 avril 1985 et fut accompagné d'une importante mobilisation, organisée par les organismes [de défense des droits de l'Homme], dirigée vers le tribunal et arborant en tête de cortège le slogan « Procès et châtiment pour tous les coupables du terrorisme d'État ", qui montrait leur soutien au procès mais aussi leur volonté que les poursuites pénales ne se limitent pas aux commandants $\underline{21}$.

On voit donc que si cette marche, qui aurait réuni environ 50.000 personnes22, marque bien un soutien à la politique gouvernementale de poursuites contre les dirigeants militaires, elle cherche néanmoins à en pointer les limites en en proposant le dépassement, la généralisation.

Si le procès semble donc bien susciter un intérêt citoyen, tous les acteurs qui interviennent à son sujet ne s'accordent nullement sur sa qualité de marqueur d'accomplissement de la démocratisation. Il va même contribuer à dégrader les rapports d'une partie significative du « MDH » aux institutions républicaines. Pour cette frange que nous allons aborder maintenant, ce procès représentatif d'une supposée culture judiciaire qui s'enracinerait dans la société n'est en rien la concrétisation des revendications associées à une culture des droits ayant émergé pendant la dictature.

\section{Le procès : divorce consommé de la culture des droits et de la culture judiciaire ?}

On l'a déjà évoqué, l'émergence du « $\mathrm{MDH}$ » pendant la dictature a marqué le développement en Argentine d'une culture des droits qui instaure un rapport nouveau - au moins dans sa présence dans le débat public - de distanciation vis-à-vis de la violence politique (aussi bien militaire qu'insurrectionnelle). Cette émergence a souvent été reliée, dans les études sur le sujet²3, à une évolution globale de la société vers une réévaluation des procédures légales formelles - la possibilité de recourir au tiers étatique en cas de litige devenant un objectif immédiat et un levier de changement légitime - pour le règlement des problèmes de la collectivité, que nous résumons par l'expression « culture judiciaire ». S’il me paraît difficile dans ces lignes d'aborder « la société » dans son ensemble, il me semble toutefois qu'il serait productif de confronter les éléments concrets qui expriment cette culture judiciaire - soit les vicissitudes du procès - aux acteurs concrets porteurs de la nouvelle culture des droits - soit les organisations qui se réclament de la défense des droits de l'Homme à l'époque ou, en tout cas, les personnes qui prennent la parole au nom de ces organisations. Nous allons ici nous focaliser sur les traces concrètes de la réception du procès par une de ces organisations, Madres de Plaza de Mayo, généralement considérée à la fois comme la plus emblématique et comme la plus radicale des associations qui constituent le « MDH ». Retrouve-t-on chez les Madres la perception du procès comme marqueur d'accomplissement de la démocratisation ? Assez peu, en vérité : si ce procès constitue bien un enjeu démocratique pour elles, son déroulement et sa conclusion vont en faire un marqueur démocratique avorté et un point d'inflexion dans le désenchantement suscité progressivement par les institutions de l'État de droit.

Le procès représente sans aucun doute un enjeu primordial pour les Madres: il est même entouré d'un processus actif de mobilisation collective. Parmi quelques exemples, on peut citer la marche, déjà mentionnée, du 22 avril 1985 ou l'encerclement du Palais de Justice le 5 août, jour où elles perturbent la séance en criant les noms des disparus avec un mégaphone24. La mobilisation autour du procès n'est donc pas seulement une initiative de soutien : elle interfère et critique, elle cherche à en orienter les décisions finales, ce qui montre bien qu'il est perçu comme un enjeu central du processus de démocratisation.

Le procès, loin d'être un non-événement pour les Madres, suscite donc une pléthore de réactions. Néanmoins, le simple fait qu’il ait lieu ne suffit pas à les satisfaire, à l'inverse des auteurs cités plus haut : la mise en scène du tribunal, la reconnaissance formelle des droits qu'elles réclament 
et l'indépendance affichée du pouvoir judiciaire vis-à-vis de l'exécutif ne compensent en rien la faiblesse des peines auxquelles sont condamnés les inculpés. Le respect de la procédure pénale n'a que peu de valeur s’il n'aboutit pas à une condamnation sévère et généralisée (seule à même de confirmer juridiquement l'existence du droit à la vie comme droit fondamental) 25 : il est même contre-productif, au sens où l'instance judiciaire, que les Madres considéraient jusque-là avec un scepticisme mêlé d'espoir26, devient dès lors une institution ennemie. En témoignent les déclarations de Hebe de Bonafini, leader des Madres, dans l'année qui suit ; elle y reprend une rhétorique anti-procédurale plus caractéristique d'une critique marxiste des droits de l'Homme que du discours d'une militante de la cause de ces mêmes droits. En janvier 1987, elle assène ainsi que " la justice telle qu'elle est ne sert à rien, parce que c'est une justice bourgeoise, faite par les bourgeois et pour les bourgeois »27. Cette défiance se double parfois d'un mépris teinté d'ironie : « Aujourd'hui, dix ans après [que nos enfants] ont disparu, je ne sais toujours pas ce qu'est et à quoi sert un habeas corpus »28. Avant même, dès le mois de janvier 1986, le journal des Madres signalait déjà que le procès était bien, pour l'association, un marqueur démocratique avorté : « On se souviendra de ce 9 décembre [jour où la sentence est rendue publique] comme d'une date malheureuse, peut-être l'antichambre d'un effondrement de l'espoir de pouvoir construire une démocratie sans renverser complètement le capitalisme dépendant » 29 .

Les conclusions que les Madres tirent du procès, marqueur avorté de la démocratisation, les mènent à une inflexion importante dans la physionomie de leur propre organisation, qui aura par la suite des répercussions non négligeables sur l'ensemble du « MDH ». On peut voir cette évolution au niveau des slogans exprimant leurs revendications. Deux jours après que la sentence ait été prononcée se tient la cinquième Marche de la Résistance organisée par les Madres, qui devaient mobiliser derrière la formule habituelle, " Juicio y castigo a los culpables ». Au dernier moment, la consigne est modifiée pour devenir " Cárcel a los genocidas » 30 : dans un geste de rejet face à la clémence du tribunal, les Madres délaissent leur appel à la médiation judiciaire pour réclamer, directement, le châtiment31. Ce slogan, loin de n'être qu'épisodique, se maintiendra par la suite pour devenir, au fil des années, une expression emblématique d'une partie du " MDH ». Si on réclame toujours un châtiment pour les coupables, la médiation judiciaire a disparu de la revendication : avec elle, c'est tout un discours de légitimation du Droit et d'appel aux institutions chargées de le faire respecter qui s'évapore, bien qu'on continue à réclamer la tenue de procès.

Bien avant que les mesures établissant l'impunité des crimes de la dictature ne soient prises par les gouvernements successifs, une partie du « MDH » s'est déjà retournée contre le régime juridico-politique post-autoritaire. Cette évolution, primordiale en ceci qu'elle fait écho à la radicalisation anti-libérale du «MDH » qu'on situe généralement dans les années 199032, est pourtant peu abordée dans les travaux académiques sur le « MDH » et la «transition démocratique ». En effet, pour en retrouver la trace, il faut soit se référer à des travaux produits par l'association Madres elle-même, ou par des intellectuels militants qui en sont proches33, soit aller directement aux sources de l'époque : journal de l'association ou revues sympathisantes34. Dans la section qui suit, nous voudrions identifier les logiques de circulation du savoir académique qui contribuent à la reproduction et à la banalisation de la vision (ou mémoire) mythifiée et réconciliée du procès. Nous qualifierons cette vision de " procéduraliste », au sens où elle valorise la procédure judiciaire formelle en tant que telle, indépendamment des sentences concrètes auxquelles elle donne lieu. En ceci, elle s'oppose au point de vue des acteurs le plus souvent mentionnés quand on parle de culture des droits en Argentine (notamment les Madres) : ceux-ci tendent en effet à adopter une position bien plus " substantialiste ", plus attachée au contenu concret de la sentence, et donc plus critique à l'égard du procès. La culture judiciaire que la mémoire procéduraliste des universitaires défend tout en la présentant comme un fait social consensuel, se trouverait donc en porte-à-faux vis-à-vis d'une culture des droits plus attachée à l'importance de la peine comme garant du rétablissement de la normativité démocratique.

Nous nous concentrons d'abord sur le corpus de textes universitaires évoqué précédemment, où la vision critique du procès développée par les Madres est invisible. Pour expliquer cette absence, un repérage des sources bibliographiques les plus citées dans ces textes s'impose, afin d'identifier les références qui font référence sur le sujet.

Plusieurs éléments émergent de ce repérage. De manière récurrente, les auteurs contemporains se renvoient les uns vers les autres : Crenzel cite Feld, tout comme Novaro (2009), qui s'appuie aussi sur Vezzetti, par exemple. On remarque ensuite qu'un certain nombre de références plus anciennes surnagent et sont utilisées de manière répétée. C’est surtout vrai pour un texte d’Inés González Bombal, "'Nunca más' : el juicio más allá de los estrados », extrait d'un ouvrage collectif datant de 199535, qui est cité par tous les auteurs de notre corpus36. En outre, d'autres contributions à cet ouvrage servent aussi de référence ici ou là : Vezzetti renvoie à la préface écrite par Adam Przeworski, Novaro (2010) et Feld (2004) renvoient au chapitre écrit par Elizabeth Jelin, et Feld (2004) mentionne également dans sa bibliographie l'autre article d’Inés González Bombal qui y figure, et qu'elle co-rédige avec Oscar Landi. Ce qui semble donc être la référence quand il s'agit d'aborder le procès et son contexte socio-historique est un ouvrage publié environ dix ans après les faits. Relativement tardif, il se situe néanmoins dans le prolongement de travaux antérieurs des mêmes auteurs, notamment ceux qui sont publiés en 1987 et 1989 sous la direction d'Elizabeth Jelin par le centre de recherche CEDES, aux éditions CEAL37, et en reproduit la plupart des conclusions. Le cadre d'analyse adopté par les différents auteurs dans les années 2000 se base donc en grande partie sur des travaux d'interprétation socio-historique datant des années 1990, qui reproduisent et prolongent eux-mêmes des conclusions tirées avant la fin des années 1980.

En quoi consiste ce cadre d'analyse utilisé dans des travaux à peu près contemporains (années 1980 et 1990) du procès ? Qu'est-ce qui en fait des références toujours légitimes pour des travaux publiés dans les années 2000 ?

\section{Travaux d'époque et « stratégie démocratique »}

Dans l'étude du cadre d'analyse utilisé dans les travaux des années 1980 et 1990 pour évoquer le procès, le recours à la notion de « stratégie démocratique " des savoirs académiques développée par Alejandra Oberti et Roberto Pittaluga peut s'avérer utile. Ce concept désigne une « stratégie argumentative " 38 dominante dans les travaux universitaires paraissant à partir de la fin de la dictature, dans lesquels les institutions républicaines formelles nouvellement rétablies sont valorisées à outrance, tandis que tout projet émancipateur de dépassement de ces institutions est rejeté car il conduirait nécessairement à une dérive autoritaire. La " stratégie démocratique » viserait donc à remplacer « les divers horizons utopiques par des conceptions de la politique ancrées dans la réalisation du possible, dans un réalisme de la démocratie possible "39. Les chercheurs joueraient donc, dans la « transition démocratique », un rôle politique, intellectuel, qui marque profondément leur manière d'envisager les objets étudiés. Cette thèse, formulée par Oberti et Pittaluga dans un texte où ils développent avant tout une critique de l'historiographie contemporaine des gauches argentines, me semble pouvoir s'appliquer au traitement qui est généralement réservé au procès. En effet, une rapide sélection d'extraits peut aisément montrer la manière dont le procès est présenté comme une réussite unanimement reconnue, le transformant en événement quasi sacré de l'histoire argentine récente. Cette vision doit par ailleurs, pour être comprise, être reliée à la position des auteurs étudiés à l'intérieur du champ politico-universitaire, afin de tester la validité de l'hypothèse de la " stratégie démocratique » appliquée à notre étude de cas.

De ce processus de sacralisation du procès par ceux qui écrivent à son sujet, l'article multi-cité d’Inés González Bombal contient à lui seul un nombre conséquent d'exemples éclairants. On y repère cette tonalité méliorative quand elle affirme que " le Procès des Juntes a eu des effets symboliques cruciaux pour l'ordre politique, il a démontré que les prémisses de base de l'État de droit pouvaient passer de l'énonciation aux actes $» 4 \underline{0}$ : elle élude ainsi les critiques qui ont été faites de la sentence, critiques qui pourraient justement remettre en cause cette idée du passage " des paroles aux actes ». Ce qui est encore plus intéressant chez González Bombal, c'est qu'elle inscrit ce succès judiciaire dans une généalogie particulière : « le Procès des Juntes a constitué le moment où la lutte pour les droits de l’Homme en Argentine a atteint son impact maximal dans l'opinion nationale et internationale "41․ Le procès est donc présenté comme la consécration de la lutte initiée par les organismes de défense des droits de l'Homme pendant la dictature : c'est le couronnement d'une trajectoire militante, qui obtient enfin une reconnaissance universelle. " Le discours des droits de l’Homme, ainsi que la conscience universelle des droits qu'il a générée, a été intimement associé à la 
réinstauration d'une dimension juridique dans la politique » $4 \underline{2}$ : c'est ainsi qu'émerge la « culture politique de la transition »43, qui s'incarne dans le procès.

Une telle approche peut étonner au premier abord pour une étude qui sert encore de référence plus de dix ans après sa publication, en ceci qu'elle inscrit le procès dans un horizon socio-culturel de niveau macro-social, laissant de côté le contenu concret du processus judiciaire, et notamment la sentence à laquelle il aboutit. Les réactions immédiates qu'il suscite et qui, comme on l'a vu, sont moins unanimes, ne sont pas évoquées non plus. À quelles explications peut-on recourir pour comprendre ce biais ?

Dans un premier temps, il convient de noter que, jusqu'à une date relativement récente, les approches empiriques de niveau micro-social sur les organisations de défense des droits de l'Homme en Argentine sont rarissimes44. Priment en effet les approches généralisatrices, axées notamment sur la notion de " culture politique », qui abordent ces groupes en les réunissant dans l'objet « MDH », une nébuleuse dont les contours restent toujours très vagues, tout comme les logiques et dynamiques de différenciation internes du " mouvement ». Ce flou homogénéisant contribue, en outre, à construire l'évidence de la coïncidence culture des droits/culture judiciaire, qui ne traduit pourtant, tout au plus, qu'une partie des positions au sein du prétendu « MDH ». González Bombal participe donc, par son approche, à la consolidation de cette tendance à la généralisation rapide et à l'omission des conflits internes au " MDH », mais elle en subit aussi probablement l'influence omniprésente. Cette explication par les lacunes méthodologiques des travaux existants ne se suffit toutefois pas à elle-même ; tout en signalant un manque symptomatique, elle ne nous en révèle nullement le facteur causal.

Cette première réponse doit donc se doubler d'une seconde hypothèse, selon laquelle le texte de González Bombal s’inscrirait directement - et non plus indirectement, par l'internalisation involontaire d'un héritage intellectuel - dans les procédés propres à la "stratégie démocratique " décrite par Oberti et Pittaluga. Un élément de poids vient donner du crédit à cette thèse dans le cas présent : le contexte institutionnel de publication du texte. En effet, celui-ci est inclus dans un ouvrage collectif qui réunit des contributions de chercheurs tous financés par le CEDES45. Or, ce centre de recherche privé, d'orientation progressiste, a constitué un des viviers dans lesquels le gouvernement radical (19831989) a puisé des conseillers présidentiels, voire des secrétaires d'État $4 \underline{6}$ au moment de la reconstruction post-autoritaire. Cette proximité du CEDES vis-à-vis du pouvoir vient donc renforcer l'idée d'un positionnement « partisan » dans le traitement du procès. Qu'il vise à préserver la mémoire du Président de l'époque, étroitement associé à cette politique judiciaire et très décrié par sa gauche - entre autres - dans les années suivantes, qu'il cherche à défendre une vision de la « bonne » sortie d'un régime autoritaire, ou qu'il cherche à justifier des prises de position passées, le texte est, quoi qu'il en soit, inscrit dans un réseau extrêmement dense d'interventions intellectuelles dans l'espace politique, et doit donc être analysé en tant que tel au moins autant que comme contribution scientifique à la connaissance historique. C'est cette ambiguïté dans la posture du chercheur qui permet d'ailleurs d'envisager le matériau universitaire en tant que matériau de production et de diffusion d'une mémoire (nécessairement) partielle et partiale : la référence doit être entendue comme bibliographie, certes, mais aussi comme source primaire.

Cette « stratégie démocratique » est d'autant plus efficace qu'elle est, en ce qui concerne le procès, hégémonique dans le champ académique des sciences sociales : aucun contre-récit ne vient la concurrencer à l'intérieur de ses propres règles codifiées. Ces contre-récits, qui envisagent le procès comme déception et comme involution démocratique, circulent à travers des canaux extérieurs. On en trouve quelques traces dans le champ proprement juridique, avec le travail critique de Marcelo Sancinetti47, mais celui-ci ne s'intéresse pas à la réception et aux répercussions sociales du procès. Celles-ci ne sont évoquées - de manière un tant soit peu appuyée - que dans les médias militants que sont le journal des Madres ou la revue Crisis. Les deux régimes de récit socio-historique (« stratégie démocratique » et critique du procès) évoluent donc dans des sphères étrangères l'une à l'autre : les deux corpus n’entrent jamais en contact.

Comment expliquer que les ressources offertes par la perspective critique ne soient pas ressaisies dans les travaux plus récents, qui pourraient se défaire du biais provoqué par la " stratégie démocratique »? Ou inversement, comment expliquer que le recours légitime à ces ressources relativement datées et marquées par un biais politique aussi net se perpétue?

\section{Trajectoires de l'évidence : opinion, référence, sens commun}

Posée d'une autre façon, la question pourrait être la suivante : pourquoi le premier type de références s'impose-t-il sur le deuxième dans les travaux académiques récents ? On tentera de répondre à cette question en excluant le facteur des affinités politiques des auteurs, marquées pour certains. En effet, si ceci permettrait d'expliquer que certaines versions de l'Histoire soient privilégiées par rapport à d'autres, les analystes pourraient néanmoins être obligés de citer des contre-analyses, si celles-ci s'imposaient d'une façon ou d'une autre. L'implication politique des auteurs n'empêcherait pas, dans ce cas, l'apparition de controverses - plus ou moins intenses - et donc la reproduction et la diffusion de ces contre-récits qu'il leur serait difficile de passer sous silence. À l'inverse, l'absence de controverse illustre, quand son absence est constatée là où elle pourrait avoir lieu - c'est-à-dire quand le matériau objectif qui la rendrait possible existe par ailleurs, ce qui est le cas ici - un rapport de forces entre les réseaux de diffusion des textes qui s'exprime par le silence. Plutôt que les affinités politiques, ce sont donc deux autres paramètres qui vont être abordés ici : le positionnement scientifique et le positionnement éditorial des textes des années 1980-1990 qui servent de référence aux auteurs plus récents.

Reprenons le texte d'Inés González Bombal, par exemple. Nous avons vu que ce texte relevait autant sinon plus de l'intervention intellectuelle que de la contribution scientifique, ce qui ne l'empêche pas de se voir reconnaître une validité scientifique par ceux qui le citent encore aujourd'hui. Cette intervention est, toutefois, d'un type particulier, en ceci qu'elle n'obéit pas aux règles « classiques » de l'engagement intellectuel dans l'espace public. Celles-ci supposent que le chercheur « sorte » de son champ de spécialisation disciplinaire pour intervenir dans une sphère publique plus large. Cet engagement obéit à des codes qui lui sont propres et qui coexistent de manière relativement autonome avec le contexte de production des savoirs académiques au sens strict : le savant et l'intellectuel ont beau être la même personne, ils se situent, en tant que rôles sociaux, dans des espaces d'intervention différenciés 4 s. Ce qui est donc particulier dans le cas présent, c'est que l'intervention politique se fait depuis l'intérieur du champ disciplinaire des sciences sociales, sans " prétentions politiques », en quelque sorte. La prise de position intellectuelle ne se présente pas comme telle : elle affiche la neutralité propre à une certaine conception de l'activité scientifique. Le regain d'intérêt et de prestige dont jouit cette conception en Argentine après la dictature a été bien analysé par Omar Acha et Paula Halperin. Ceux-ci mettent l'accent sur le paradoxe qu'elle abrite : celui d'un chercheur dont les modes de légitimation se veulent indépendants de la politique, mais dont le positionnement traduit, bien évidemment, un certain rapport à la politique et un rapport positif à une certaine politique : celle qui valorise l'autonomie procédurale du savoir vis-à-vis du pouvoir et, entre autres, du judiciaire vis-à-vis de l'exécutif4.9. La valorisation du "professionnalisme » dans les sciences sociales se traduit donc par un reniement des implications et des modes de constitution politiques du savoir : sans une reconstruction de ceux-ci, la référence " savante » peut alors se maintenir comme référence légitime et suffisante à elle-même parce qu'affichant une pseudo-neutralité professionnelle.

Pour rendre compte de cette construction politique de l'apolitisme scientifique, comme nous avons essayé de le faire jusqu'ici, on est obligé d'aller chercher les contre-récits et les contre-sources dans des circuits de médiation alternatifs. À l'inverse, la légitimité professionnelle dont jouit le texte, pour y revenir, d'Inés González Bombal, en fait un matériau citable sans que soit nécessaire la production de contreargumentations fournies par d'autres sources, moins légitimes5o. À moins que le contre-récit n'accède à des moyens de diffusion qui en rendent la mention inévitable - ce qui pourrait obliger celui qui cite à complexifier radicalement la trame historique présentée -, celle-ci s'avère donc superflue pour bâtir un travail scientifique crédible. Une des raisons pour lesquelles la vision critique du procès n'est pas citée est donc que, du point de vue de la légitimation du travail universitaire, elle est inutile. 
Ceci nous amène à aborder la question des canaux de diffusion des différents discours sur le procès. On se trouve alors confronté au cas d'une diffusion éditoriale de textes académiques qui étonne par sa massivité. En effet, en 1984, les éditions CEAL lancent une nouvelle collection, la Biblioteca Política Argentina, publiant à un rythme hebdomadaire des livres vendus jusqu'à 40.00o exemplaires par semaine51. L'immense majorité de ces ouvrages est écrite par des chercheurs en sciences sociales, parmi lesquels se trouvent nombre des auteurs ici évoqués. La diffusion de ces travaux faits en " langage » académique n'a donc rien à envier à celle des contre-récits de l'époque : elle tendrait même plutôt à les écraser52. Si on ajoute à cela la pérennité du support-livre par rapport au support-journal, le contraste est évident. Les ouvrages édités par CEAL sont accessibles, aujourd'hui encore, dans une multitude de bibliothèques, ce qui n'est pas le cas des collections du journal des Madres, seulement disponibles dans quelques fonds d'archives. Récit intellectuel et contre-récit militant jouissent donc de circuits de diffusion sans commune mesure.

C'est dans cette diffusion massive et cette disponibilité pérenne qu'on peut voir une des raisons pour lesquelles les descriptions louangeuses du procès «survivent » mieux que les autres, et font sens-commun. La réception positive du procès est un trait de la mémoire argentine de la « transition démocratique » qui, en outre, se perpétue par les multiples références contemporaines qui sont faites aux premiers travaux publiés sur le sujet, qui viennent appuyer des assertions reproduisant l'évidence par la citation, dans un circuit de médiation fermé. C'est ainsi que l'affirmation d'Hugo Vezzetti pour lequel le procès est un « événement fondateur qui, envisagé aujourd'hui, prend la dimension d'un mythe "53 peut adopter la forme d'une description neutre, et emporter la conviction parce qu'elle se présente sous cette forme. Dans ce geste, qui tient à la fois du constatif et du performatif - perlocutoire -, se joue la production toujours renouvelée d'une mémoire positive du procès54, qui en valorise la procédure formelle et la pose comme emblème d'une culture judiciaire nouvelle et socialement partagée, héritant du prestige acquis par les organisations de défense des droits de l'Homme dans leur lutte contre la dictature. Vezzetti, en un sens, a raison : le procès est bien devenu un des «mythes» fondamentaux de la post-dictature. Mais son analyse est incomplète, dans la mesure où il élude le processus de " mythification » qui a eu lieu : en ramenant le « mythe » aux simples qualités du procès, il occulte la circulation, la perpétuation et l'hégémonie d'une interprétation partiale55 qui ont permis d'en gommer le caractère controversé et conflictuel. C'est l'existence de ce processus que l'article présent a cherché à mettre en évidence.

\section{Conclusion}

Le Procès des Juntes est souvent présenté comme un événement central dans l'Histoire de la post-dictature argentine, et la culture judiciaire comme un élément fondamental du « MDH ». Ce constat de départ suscite un double questionnement.

Dans quelle mesure cette centralité, apparemment évidente, est-elle une construction ? Le problème est envisagé à travers la confrontation de deux corpus, l'un universitaire, l'autre militant. On constate que, certes, le procès est vécu, des deux côtés, comme un moment important de la politique argentine ; mais il l'est d'une manière bien différente selon le « camp » qui est envisagé. C'est dans cette différence qu'on voit émerger, d'un côté, une culture judiciaire procéduraliste, que ne partagent pas, de l'autre côté, les figures du «MDH » ici étudiées, représentatives d'une culture des droits bien plus substantialiste. En effet, la tenue de procès ne suffit pas, en tant que telle, à satisfaire les revendications des Madres de Plaza de Mayo, si elle n'est pas suivie de peines conséquentes. La vision pacifiée du procès est donc une construction : celui-ci a suscité, lors de son déroulement, des conflits virulents et une déception marquée pour certains.

En quoi la littérature universitaire a-t-elle contribué à cette construction ? Comment expliquer sa réussite ? L'analyse critique du corpus académique, dans son texte et dans son paratexte, mène vers deux types de conclusions. Tout d'abord, l'intervention politique est d'autant plus efficace qu'elle jouit d'une légitimité scientifique : la défense du procès repose en partie sur ce mécanisme, qui neutralise les interventions militantes, moins légitimes donc moins citables. Ensuite, l'inégale grandeur des circuits de diffusion éditoriale des deux corpus contribue, avec le temps, à effacer les contre-récits. La légitimité des pratiques auto-référentielles des intellectuels universitaires s'en trouve redoublée : l'opinion, faute de contradiction, mue en vérité de sens-commun. Ainsi, l'inexistence d'une contre-Histoire du procès jouissant du même degré d'articulation que le récit dominant semble faire de la culture judiciaire une composante essentielle du « MDH », chose qu'elle n'est pas.

D'autres constats, plus généraux, font signe vers des recherches futures. Premièrement, la défense des droits de l'Homme est parfois assimilée, trop vite, à la défense des droits de la défense en contexte judiciaire : une posture « droit-de-l'hommiste » peut pourtant cohabiter avec certaines formes de punitivisme pénal.

Deuxièmement, le découpage séquentiel habituel de la politique des droits de l’Homme en Argentine dans les années 1980 (émergence contestataire du « MDH » jusqu'à la fin 1983; consensus entre État et « MDH » jusqu'en 1986 ; puis réactivation de la confrontation) doit être revu de manière critique, car il occulte un certain nombre de situations qui lui font interférence. L'épisode du Procès des Juntes analysé ici remet ainsi en cause l'idée d'un " consensus alfonsiniste » sur les droits de l'Homme jusqu'en 1986, séquence emblématique qui perd beaucoup de sa cohérence quand on l'envisage à travers les points de vue différents construits à son sujet.

Enfin, quand on parle de " médias », on se réfère le plus souvent aux différents types de médias " de masse » : télévision, presse nationale ou régionale, etc. L'association aux questions mémorielles n'est alors pas étonnante, car l'idée de mémoire sociale implique aussi la possibilité d'une mémoire « de masse ». Ici, c'est l’impact d'un média de circulation plus restreinte mais aux effets très larges sur les schémas de perception, de périodisation et de mobilisation au présent de l'Histoire qui a été analysé : en l'occurrence, les publications des chercheurs en sciences sociales, qui agissent à la fois comme médiatrices du savoir historique et comme bâtisseuses de mémoire sociale, au même titre que l'État ou les mouvements sociaux qu'on associe plus souvent aux politiques de la mémoire. S'ouvre alors un programme historiographique de critique de la production académique sur les droits de l'Homme et la mémoire en Argentine, prenant l'analyse du Procès des Juntes pour point de départ méthodologique.

\section{Notes}

1 J'utilise ici des guillemets car l'usage de cette expression, omniprésente dans la littérature, me semble poser un certain nombre de problèmes qui seront évoqués plus loin.

2 Expression tirée de Novaro Marcos, « Formación, desarrollo y declive del consenso alfonsinista sobre derechos humanos », in Gargarella Roberto, Murillo María Victoria, Pecheny Mario (dir.), Discutir Alfonsín, Buenos Aires, Siglo XXI, 2010.

3 Ce travail ne prétend pas fournir une analyse de ce que peut être une culture politique dans toute sa complexité, et avec la complexité qui peut être associée aux différentes conceptualisations de cette notion. Nous pensons toutefois que l'usage, ici, du terme « culture » est utile en tant que mot-clé renvoyant à un ensemble de dispositifs discursifs que leurs promoteurs ou analystes - ou les deux, comme nous le verrons - associent toujours à une certaine diffusion sociale au-delà de leurs simples protagonistes (leaders politiques, magistrats), voire à une certaine universalité.

4. Feld Claudia, Del estrado a la pantalla: las imágenes del juicio a los ex comandantes en Argentina, Madrid, Siglo XXI, 2002.

5 Novaro Marcos, Argentina en el fin de siglo : democracia, mercado y nación (1983-2001), Buenos Aires, Paidós, 2009, pp. 100-170. 
$\underline{6}$ Voir à ce sujet : Sancinetti Marcelo, Derechos humanos en la Argentina post-dictatorial, Manuel Lerner, 1988.

7. Ainsi du général Camps et du commissaire Etchecolatz, qui sont condamnés respectivement à 25 et 23 ans de prison. Mentionné par Feld Claudia, La Télévision comme scène de la mémoire de la dictature en Argentine : une étude sur les récits et les représentations de la disparition forcée de personnes, Thèse de Doctorat en Sciences de l'Information et de la Communication, Université Paris 8, 2004, p. 159.

$\underline{8}$ Ibid.

9. Crenzel Emilio, La Historia política del Nunca Más : la memoria de las desapariciones en la Argentina, Buenos Aires, Siglo XXI, 2008.

10 Feld Claudia, La Télévision comme scène de la mémoire, op. cit. et Del estrado a la pantalla, op. cit.

11 GARgarella Roberto, « Democracia y derechos en los años de Alfonsín », in Gargarella Roberto et al., Discutir Alfonsín, op.cit.

12 Novaro Marcos, « Formación, desarrollo y declive », op. cit. et Argentina en el fin de siglo, op. cit.

13 Vezzetti Hugo, Pasado y presente: guerra, dictadura y sociedad en la Argentina, Buenos Aires, Siglo XXI, 2002.

14. GARGARELLA Roberto, « Democracia y derechos », op. cit., p. 28.

15 Vezzetti Hugo, Pasado y presente, op. cit., p. 137.

$\underline{16}$ Ibid., p. 140.

17. VezzetTi Hugo, Pasado y presente, op. cit., p. 135.

$\underline{18}$ Pour plus d'informations sur la décision de filmer le procès et de diffuser les images sans le son, voir Feld Claudia, La Télévision, op. cit., pp. 163167.

19. Ibid., p. 155 .

20 Ibid.

211 CRENZel Emilio, La Historia política del Nunca Más, op. cit., p. 138.

$\underline{22}$ Selon une information du quotidien Clarín reprise par Emilio Crenzel dans ses notes. Marcos Novaro remarque qu'une deuxième mobilisation massive a lieu en septembre 1985, au moment où sont écoutés les derniers témoignages. Comme nous le verrons plus avant, celle-ci va toutefois avoir un sens assez différent, et témoigner d'un durcissement du discours sur la justice émanant du « MDH ». Voir à ce sujet : Novaro Marcos, Argentina en el fin de siglo, op. cit., p. 149.

23 Voir par exemple : Novaro Marcos, Palermo Vicente, La dictadura militar, 1976-1983 : del golpe de estado a la restauración democrática, Buenos Aires, Paidós, 2003.

24. Voir à ce sujet : Gorini Ulíses, La otra lucha : historia de las Madres de Plaza de Mayo, Tomo II (1983-1986), Buenos Aires, Norma, 2011, p. 374

25 Dans l'édition de Mai 1985 du journal Madres de Plaza de Mayo, on peut lire que « le 22 avril [jour où débutent les audiences] pourrait se transformer en date historique pour l'Argentine. Mais il peut aussi finir par n'être qu'une date d'ignominie si le projet de faire culminer ce processus judiciaire par une 'ample et généreuse' amnistie aboutit ». Guilis Alberto, « Juicio a las cúpulas militares : el valor de la memoria », Madres de Plaza de Mayo, $\mathrm{n}^{\circ} 6$, mai 1985 , p. 2.

$\underline{26}$ « 'Archivez le dossier', dit le juge cet après-midi-là. Et tout a pris fin. Y compris les illusions ». Ángel Raquel, « El fin de las ilusiones », Madres de Plaza de Mayo, $\mathrm{n}^{\circ} 14$, janvier 1986, p. 5 .

27. De Bonafini Hebe, « Respuesta al presidente », Crisis, 1987, nº50, p. 62.

$\underline{28}$ Ibid., p. 5 .

29. González Gartland Carlos, « De sentencias y puntos finales », Madres de Plaza de Mayo, nº 14, janvier 1986, p. 4.

$3 \underline{0}$ « Prison pour les génocidaires » [traduction de l'auteur].

31 Voir à ce sujet : Gorini Ulíses, La otra lucha, op. cit., p. 450.

$3 \underline{2}$ Voir à ce sujet : Lvovich Daniel, Bisquert Jaquelina, La Cambiante memoria de la dictadura : discursos públicos, movimientos sociales y legitimidad democrática, Buenos Aires, Biblioteca Nacional, 2008.

33 Ainsi de l'histoire des Madres écrite par Ulíses Gorini, journaliste proche de l'organisation, qui la co-publie.

34. C'est le cas de Crisis, qui relaie leurs prises de position et rend compte de leurs activités.

35 Acuña Carlos, González Bombal Inés, Jelin Elizabeth et al., Juicio, castigos y memorias : derechos humanos y justicia en la política argentina, Buenos Aires, Nueva Visión, 1995.

$3 \underline{6}$ Sauf par Gargarella, qui ne mentionne aucune source, à l'exception des articles de loi auxquels il se réfère.

37. Nous faisons ici référence à Los nuevos movimientos sociales : Mujeres. Rock Nacional. Derechos humanos. Obreros. Barrios, Buenos Aires, CEAL, 1989, et à Movimientos sociales y democracia emergente, Buenos Aires, CEAL, 1987, tous deux dirigés par Elizabeth Jelin.

$3 \underline{8}$ Oberti Alejandra, Pittaluga Roberto, Memorias en montaje : escrituras de la militancia y pensamientos sobre la historia, Buenos Aires, El Cielo por Asalto, 2006, p. 134.

39. Ibid.

4oㅡ González Bombal Inés, « 'Nunca Más’: el juicio más allá de los estrados », op. cit., p. 212.

41 Ibid., p. 209.

$4 \underline{2}$ Ibid., p. 215 . 
43 Ibid.

44. Des travaux tels que ceux de Luciano Alonso, qui se focalise sur la province de Santa Fe, ou de Santiago Cueto Rúa, qui fait une étude détaillée de l’organisation HIJOS dans la ville de La Plata, n’apparaissent que dans les années 2000.

45 Centro de Estudios del Estado y la Sociedad.

$4 \underline{6}$ Voir à ce sujet : Elizalde Josefina, « La participación política de los intelectuales durante la transición democrática : el Grupo Esmeralda y el presidente Alfonsín », Temas de historia argentina y americana, ${ }^{\circ}{ }_{15}$, 2009, pp. 53-87.

47. Sancinetti Marcelo, Derechos humanos, op. cit.

$4 \underline{8}$ On peut, par exemple, difficilement évaluer de la même manière des textes de Sartre tels que L’Être et le néant et « Élections piège à cons ».

4.9. Voir à ce sujet : Acha Omar, Halperin Paula, « Retorno a la democracia liberal y legitimación del saber : el imaginario dominante de la historiografía argentina », Protohistoria, $n^{\circ} 3,1999$.

$5 \underline{0}$ Cette citabilité de la référence originale contribue d'ailleurs à légitimer le point de vue de celui qui cite : on devrait sans doute réfléchir à l'effet de conviction que peut déclencher une simple référence en note de bas de page - dispositif s'il en est attestant du " professionnalisme » de celui qui écrit.

$5 \underline{1}$ Gociol Judith et al., Más libros para más : colecciones del Centro Editor de América Latina, Buenos Aires, Biblioteca Nacional, 2007 , p. 293.

52 Le journal des Madres ne dépasse pas les 10.000 exemplaires vendus par mois ce qui, ramené à la semaine, est seize fois inférieur aux chiffres des publications CEAL. Pour les chiffres, voir : D’aloisio Fabián, Nápoli Bruno, " La construcción del discurso político de la Asociación Madres de Plaza de Mayo a través de su prensa oficial ", in Actes des ive Jornadas de Estudio de las Izquierdas du CEDINCI, 14-16 novembre 2007, Buenos Aires.

53 Vezzetti Hugo, Pasado y presente, op. cit., p. 137.

54. Constatif, parce qu'au moment de la citation (2002), le mythe existe déjà. Mais performatif également, parce que le constat lui-même contribue à (re)produire le mythe qu'il décrit.

55 Comme toute interprétation : le problème n'est pas là.

\section{Pour citer cet article}

David Copello, «Lectures du Procès des Juntes en Argentine : production intellectuelle, (re)productions mémorielles», Cahiers Mémoire et Politique [En ligne], I. Consensus mémoriel et logiques de (re)production, Cahier $\mathrm{n}^{\circ} 2$. Médias en jeu, enjeux de mémoires, 31-49 URL : https://popups.uliege.be:443/2295-0311/index.php?id=102. 